\title{
PERFIL DE UTILIZAÇÃO DE MEDICAMENTOS GENÉRICOS EM 31 FARMÁCIAS DA CIDADE DE CURITIBA
}

THE PROFILE OF GENERIC MEDICINE USE IN 31 DRUGSTORES OF THE CITY OF CURITIBA

MONTRUCCHIO, Deise Prehs'; MIGUEL, Marilis Dallarmi2; ZANIN, Sandra Maria Warumby²

'Professora de Estágio em Farmácia do Departamento de Farmácia da UFPR

${ }^{2}$ Professora de Farmacotécnica do Departamento de Farmácia da UFPR

\section{RESUMO}

A utilização de medicamentos genéricos no Brasil vem crescendo ano a ano, reduzindo custos relativos à saúde, embora represente ainda apenas uma pequena parcela das prescrições médicas. Atualmente existem disponíveis no mercado brasileiro mais de 230 fármacos e 2.800 apresentações de medicamentos genéricos, cobrindo a maior parte das doenças identificadas na população brasileira. O objetivo deste trabalho foi fazer um levantamento das principais classes terapêuticas e fármacos comercializados nas farmácias de Curitiba como medicamentos genéricos.

Palavras-chave: genéricos, fármacos, saúde

\section{ABSTRACT}

The use of generic medicine in Brazil is rising year-by-year, reducing costs related to health system, although it still represents a small parcel of medical prescriptions. Nowadays there are available on Brazilian market more than 230 active substances and 2.800 presentations of generic medicine, covering the major part of diseases identified on Brazilian population. The goal of this research was to reveal the major therapeutic classes and substances sold on drugstores of Curitiba as generic medicine.

Keywords: generic medicine, active substances, health

\section{INTRODUÇÃO}

A farmacoterapia é, sem dúvida, a maior e mais utilizada entre as alternativas terapêuticas à disposição das equipes de saúde na busca da melhoria da qualidade de vida da população. Em todos os países onde o custo médio dos medicamentos é elevado, como no caso do Brasil, os genéricos têm conquistado fatias de mercado cada vez maiores e com maior velocidade, demonstrando sua capacidade de atender a requisitos baseados fundamentalmente em preços, e garantindo perfis de segurança e qualidade do produto colocado à disposição da população.

Os medicamentos genéricos, estabelecidos legalmente no Brasil a partir de 1999, são definidos pela lei no 9787 (1) como produtos similares a produtos de referência ou inovadores, que podem ser com eles intercambiáveis, geralmente produzidos após a expiração ou a renúncia da proteção patentária ou de outros direitos de exclusividade, desde que comprovada sua eficácia, segurança e qualidade, e são designados pela Denominação Comum Brasileira ou pela Denominação Comum Internacional.

Quatro anos após a regulamentação dos medicamentos genéricos, pode-se verificar que o consumo destes medicamentos vem aumentando significativamente, assim como o número de apresentações. Atualmente são mais de 230 fármacos e mais de 800 produtos registrados pela Agência Nacional de Vigilância Sanitária (Anvisa), disponíveis em mais de 2.800 apresentações, produzidos por cerca de 38 laboratórios aprovados pela Anvisa, incluindo 56 classes terapêuticas e englobando as principais doenças identificadas na população brasileira $(3,4)$. A necessidade principal para o registro de um produto genérico, preconizado pela Organização Mundial da saúde, é a garantia de sua segurança, qualidade e eficácia, utilizando como parâmetro o medicamento de referência (7). 
Dados do Ministério da Saúde indicam que cerca de $48 \%$ da população que consome medicamentos no Brasil, quando chegam às farmácias, pedem pelos medicamentos genéricos, e cerca de $40 \%$ solicitam ao farmacêutico a troca do medicamento de "marca" pelo genérico.

Uma das grandes vantagens dos medicamentos genéricos é a significativa redução nos preços, que em geral é de 30\%, podendo chegar até $50 \%$ em alguns casos, com a segurança da mesma qualidade do medicamento de referência. Esta redução de preços deve-se principalmente ao fato de que os genéricos podem ser produzidos por outros laboratórios quando expirada a patente e o direito de exclusividade do laboratório que o pesquisou e desenvolveu. Desta forma, o custo do medicamento cai ao seu custo real de fabricação, não mais embutindo o investimento em pesquisa e divulgação $(4,6)$.

Por outro lado, para que um medicamento possa ser registrado como genérico, são necessárias provas de bioequivalência, com aferição da equivalência terapêutica e farmacêutica, de acordo com as normas estabelecidas pela resolução RDC $n^{\circ} 135$, de maio de 2003, garantindo assim a eficácia igual ao medicamento de referência (2).

O objetivo desta pesquisa foi avaliar o consumo de medicamentos genéricos em farmácias da cidade de Curitiba, avaliando as classes terapêuticas e os fármacos específicos de maior comercialização.

\section{MATERIAL E METODOS}

Foi realizado um levantamento em 31 farmácias de dispensação em Curitiba, por estagiários alunos do $3^{\circ}$ ano do curso de farmácia da Universidade Federal do Paraná, no período de outubro de 2002 a março de 2003. Em cada uma das farmácias foram levantados os 10 medicamentos genéricos de maior demanda, os quais foram ordenados segundo seu volume de comercialização, do $1^{\circ}$ ao $10^{\circ}$ lugar.

Dentre as farmácias pesquisadas encontram-se 21 lojas de uma grande rede, e mais 10 farmácias de menor porte, espalhadas em diversas regiões da cidade.

\section{RESULTADOS E DISCUSSÃO}

Dentre as 31 farmácias pesquisadas, foram citados ao total 48 fármacos entre os dez de maior demanda, divididos em 17 classes terapêuticas diferentes. Dentre estas 17 classes terapêuticas, foram ordenadas as dez classes com maior número de citações entre as mais comercializadas (tabela 1). Outras classes, como antiasmáticos, antiagregantes plaquetários, cardiotônicos, anticonvulsivantes, antihelmínticos, antivirais e hipoglicemiantes apareceram com menos de três citações entre os mais vendidos. 
Tabela 1 - Classes terapêuticas com maior número de citações

\begin{tabular}{cc}
\hline Classe terapêutica & $N^{\circ}$ de citações \\
\hline Antihipertensivos & 64 \\
Antibióticos & 58 \\
Antiinflamatórios & 57 \\
Antiulcerosos & 37 \\
Analgésicos e antitérmicos & 19 \\
Hipocolesterolemiantes & 17 \\
Antifúngicos & 10 \\
Antitussígenos & 7 \\
Antiarrítmicos & 6 \\
Ansiolíticos & 4 \\
\hline
\end{tabular}

Por outro lado, quando observamos o número de farmácias nas quais as citadas classes terapêuticas aparecem como líder de vendas, observamos uma inversão nos dados da tabela 1. Dentre as 31 farmácias pesquisadas, 12 apontam os antibióticos como líder de vendas, enquanto 10 farmácias apontam os antiinflamatórios, 5 apontam os antihipertensivos, e 3 apontam os analgésicos como a classe terapêutica com maior demanda, enquanto apenas 1 farmácia indicou os antiulcerosos como líder de vendas (tabela 2, gráfico 1).

Tabela 2 - Classes terapêuticas e número de farmácias onde aparecem como líder de vendas

\begin{tabular}{ccc}
\hline Classe terapêutica líder de vendas & $N^{\circ}$ de farmácias & Porcentagem \\
\hline Antibióticos & 12 & $38,7 \%$ \\
Antiinflamatórios & 10 & $32,3 \%$ \\
Antihipertensivos & 5 & $16,1 \%$ \\
Analgésicos & 3 & $9,7 \%$ \\
Antiulcerosos & 1 & $3,2 \%$ \\
\hline
\end{tabular}

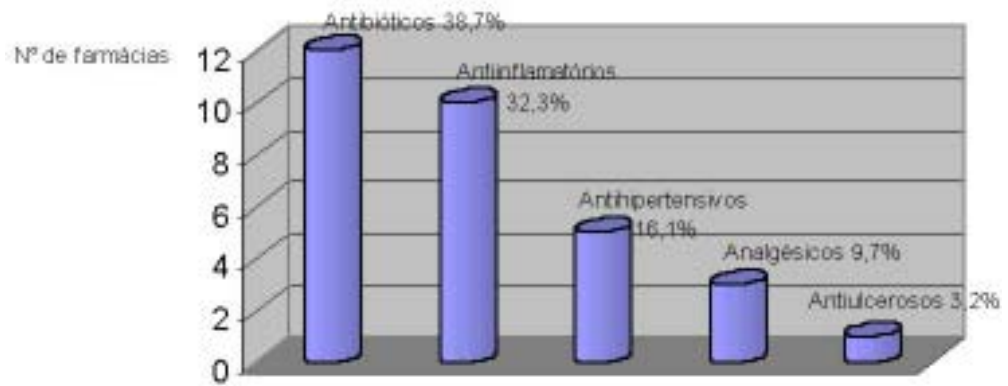

Gráfico 1 - Classes terapêuticas e número de farmácias onde aparecem como líder de vendas

Dentre as citadas classes terapêuticas, alguns fármacos também se sobressaem como produtos de maior demanda. A tabela 3 ilustra os fármacos, divididos por classe terapêutica, que aparecem entre os três de maior comercialização nas farmácias. Entre os antibióticos, a amoxicilina aparece como líder absoluto de vendas; entre os antiinflamatórios, o líder de vendas é o diclofenaco de potássio, seguido pelo diclofenaco de sódio e nimesulida; entre os antihipertensivos, o atenolol aparece como líder de vendas, seguido do captopril e do 
maleato de enalapril; entre os analgésicos o paracetamol, seguido da dipirona sódica, aparece entre os três fármacos de maior venda; e entre os antiulcerosos, a ranitidina aparece como líder de vendas, seguida do omeprazol.

Tabela 3 - Fármacos e número de farmácias onde aparecem entre os três produtos de maior venda

\begin{tabular}{lcc}
\hline \multicolumn{1}{c}{ Fármaco } & $N^{0}$ de farmácias & Porcentagem \\
\hline Antibióticos & 22 & \\
- Amoxicilina & \multicolumn{2}{c}{} \\
\hline Antiinflamatórios & 16 & $70,9 \%$ \\
- Diclofenaco de potássio & 3 & $51,6 \%$ \\
- Diclofenaco de sódio & 2 & $9,7 \%$ \\
- Nimesulida & & $6,5 \%$ \\
\hline Antihipertensivos & 11 & $35,5 \%$ \\
- Atenolol & 8 & $25,8 \%$ \\
- Captopril & 4 & $12,9 \%$ \\
- Maleato de enalapril & & \\
\hline Analgésicos & 4 & $12,9 \%$ \\
- Paracetamol & 3 & $9,7 \%$ \\
- Dipirona sódica & & $16,1 \%$ \\
\hline Antiulcerosos & 5 & $3,2 \%$ \\
- Ranitidina & 1 & \\
- Omeprazol & & \\
\hline
\end{tabular}

4 CONCLUSÃO

Os dados coletados mostram que, apesar do grande número de fármacos disponibilizados atualmente como medicamentos genéricos, há uma concentração maior de vendas de antibióticos, antiinflamatórios e antihipertensivos, ficando as outras classes terapêuticas com uma menor parte do mercado. Isto se deve, em parte, ainda pela falta de hábito dos profissionais médicos em prescrever medicamentos pela sua denominação genérica, preferindo ainda os medicamentos de referência. Dados da Anvisa revelam que cerca de $30 \%$ dos médicos brasileiros ainda relutam em prescrever medicamentos genéricos, embora $86 \%$ dos mesmos aprovem sua eficácia terapêutica. Desta forma, apenas 16\% das receitas trazem o genérico como primeira opção. Por outro lado, parte da população usuária de medicamentos não solicita, ou não aceita a permuta do medicamento de referência pelo genérico, muitas vezes por desconhecimento ou desconfiança.

Os farmacêuticos, como agentes multiplicadores de prevenção e ação primária em saúde, e como únicos profissionais legalmente autorizados a substituir medicamentos de referência por genéricos, têm como dever informar e orientar a população quanto aos mesmos, com o objetivo de permitir à população o acesso a farmacoterapêutica segura e eficiente, com custos mais acessíveis. No entanto, o que se observa na prática é que muitas vezes o farmacêutico se omite, delegando aos balconistas das farmácias a responsabilidade pela orientação ao paciente; esta atitude pode ocasionar, por sua vez, que o cliente saia da farmácia sem uma orientação correta, principalmente no que diz respeito às diferenças entre medicamentos genéricos e similares. 
Portanto, a atuação ética profissional deve estar presente já durante a formação acadêmica, fazendo-se necessário agregar à grade curricular do acadêmico de farmácia, conteúdos que privilegiem a prática. Nesse contexto evidencia-se a importância da inserção de farmácias-escola junto às universidades, como ferramenta imprescindível para oportunizar a vivência prática, sob supervisão direta docente, e a valoração das normas de conduta ética e moral no atendimento ao cliente.

A implantação dos genéricos no Brasil significa de fato, na área da saúde, um benefício à população. Aliado à atuação ética do profissional farmacêutico, é uma alternativa inconteste para o acesso racional a medicamentos nos setores público e privado, sendo uma discussão sempre presente na classe médica e nas suas entidades representativas.

\section{REFERÊNCIAS}

BRASIL, 1999. Lei $n^{\circ}$ 9787, de 10 de fevereiro de 1999. Estebelece o medicamento genérico, dispõe sobre a utilização de nomes genéricos em produtos farmacêuticos e dá outras providências.

BRASIL, 2003. Resolução RDC n 135, de 29 de maio de 2003. Aprova o regulamento técnico para medicamentos genéricos.

Dicionário de Especialidades Farmacêuticas. DEF 2002/03. $31^{\text {a }}$ edição, 1 cd-rom.

Genéricos. Pharmacia Brasileira n. 37, maio/junho 2003, p. 36-37.

Medicamentos genéricos. Disponível em www.genericos.med.br. Acesso em 09/09/2003.

Medicamento genérico. Disponível em www.medicamentogenerico.org.br. Acesso em 09/09/2003.

MENDA, M.E. (Org.). Manual médico: medicamentos genéricos. São Paulo: Lemos, 2002. 